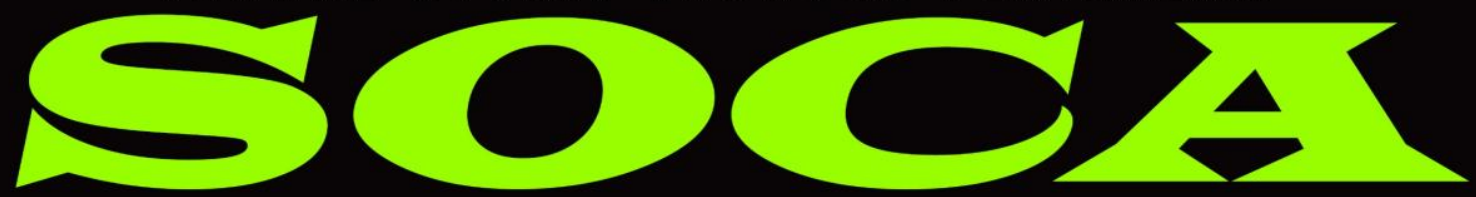

JOURNAL ON SOCIAL ECONOMICS OF AGRICULTURE

\title{
KAJIAN PENGARUH SISTEM PENGGAJIAN TERHADAP KINERJA KARYAWAN NATRABU MINANG RESTORAN BALI
}

\author{
Puja, I Nyoman Gede Ustriyana dan Dwi Putra Darmawan \\ Program Studi Agribisnis, Fakultas Pertanian, Universitas Udayana \\ Jalan P.B. Sudirman-Denpasar, 80232, Bali \\ Email: pujapramana@gmail.com, komingbudi2@yahoo.com, \\ dwiputradarmawan@yahoo.com \\ No Hp: 085375628785, 0811392593, 0818560321
}

\begin{abstract}
ABSTRAK
Penelitian ini bertujuan untuk menilai bagaimana pengaruh sistem penggajian terhadap kinerja karyawan Natrabu Minang Restoran Bali. Metode penelitian menggunakan purposive sampling yaitu teknik untuk menentukan sampel penelitian dengan beberapa pertimbangan tertentu yang bertujuan agar data yang diperoleh nantinya bisa lebih representatif, artinya sampel data yang diambil sebanyak 35 responden dari 39 karyawan. Hal ini dikarenakan empat karyawan lainnya tidak memenuhi kriteria dalam penelitian penulis. Adapun kriteria pemilihan sampel terbagi menjadi kriteria inklusi dan eksklusi. Teknik analisis data menggunakan analisis statistik deskriptif dan statistik inferensial (Sem-PLS). Metode ini dikenal sebagai pendekatan partial least square (Sem-PLS) yang merupakan metode SEM berbasis varian. Hasil penelitian menyatakan bahwa Sistem Penggajian berpengaruh signifikan terhadap pemberdayaan karyawan, terlihat dari nilai t-hitung $(12,512)>\mathrm{t}$-tabel $(1,96)$ dan nilai $\mathrm{p}$-value sebesar $0,000<$ 0,05. Sistem Penggajian berpengaruh signifikan terhadap kepuasan kerja, terlihat dari nilai t-hitung $(5,911)>$ t-tabel $(1,96)$ nilai $\mathrm{p}$-value sebesar $0,000<0,05$. Sistem Penggajian berpengaruh signifikan terhadap komitmen organisasi, terlihat dari nilai t-hitung $(8,158)>$ t-tabel $(1,96)$ nilai $\mathrm{p}$-value sebesar $0,000<0,05$. Saran yang bisa diberikan penulis adalah perusahaan dapat memprioritaskan sistem penggajian dalam peningkatan kinerja karyawan, dimana terkhususkan pada dimensi sentralisasi-desentralisasi, karena ini memiliki nilai tertinggi diantara dimensi sistem penggajian yang lainnya.
\end{abstract}

Kata kunci: sistem penggajian, pemberdayaan, kepuasan kerja, komitmen organisasi 


\title{
STUDY OF THE EFFECT OF EMPLOYMENT SYSTEMS ON PERFORMANCE OF EMPLOYEES NATURAL MINANG RESTAURANT BALI
}

\begin{abstract}
This study aims to assess the influence of the payroll system on employee performance of Natrabu Minang Restaurant Bali. The research method used purposive sampling, a technique to determine the sample of the study with certain considerations aimed at making the data obtained later more representative, meaning that the sample of data taken was 35 respondents out of 39 employees. This is because the other 4 employees did not meet the criteria in the research. The sample selection criteria are divided into inclusion and exclusion criteria. The data analysis techniques used descriptive statistical analysis and inferential statistics (Sem-PLS). This method is know as the partial least square (SEM-PLS) approach which is a variant-based SEM method. The findings show that the Payroll System has a significant effect on employee empowerment, it can be seen from the t-count value (12.512) $>t$-table (1.96) and the $p$ value of $0.000<0.05$. The payroll system has a significant effect on job satisfaction, it can be seen from the value of $t$-count (5.911) $>t$-table (1.96) p-value of $0.000<0.05$. It also has a significant effect on organizational commitment, it can be seen from the value of t-count (8.158) $>$ t-table (1.96) p-value of $0.000<0.05$. Suggestions that can be made by the author are that companies can prioritize payroll systems in improving employee performance, which is specifically on the centralization-decentralization dimensions because this has the highest value among the dimensions of the other payroll systems.
\end{abstract}

Keywords: payroll system, empowerment, job satisfaction, organizational commitment

\section{PENDAHULUAN}

Indonesia merupakan sebuah negara yang memiliki jumlah penduduk yang sangat padat, kira-kira terdapat 232,516.8 juta jiwa lebih penduduk di Indonesia, dengan jumlah penduduk yang sangat besar, Indonesia memliki potensi sumber daya manusia yang sangat besar dari segi kuantitas. Menurut data dari Human Development Indeks, Indonesia berada pada peringkat 108 di dunia dari segi kualitas sumber daya manusia. Sumber Daya Manusia (SDM) merupakan salah satu hal penting dalam reformasi ekonomi, dimana harus mampu menciptakan sumber daya manusia yang berkualitas dan memiliki keterampilan serta berdaya saing tinggi dalam persaingan global yang selama ini kita abaikan.

https://ojs.unud.ac.id/index.php/soca
Sumber daya manusia juga menjadi bagian terpenting dari suatu negara, apalagi untuk masa yang akan datang terutama pada era globalisasi. Perannya dalam mendukung sector industry sebagai penggerak utama pembangunan, serta demi tercapainya keberhasilan pembangunan di segala bidang. Oleh karena itu peningkatan sumber daya manusia merupakan salah satu persyaratan utama dalam peningkatan kinerja. Di samping itu, sumber daya manusia juga berpengaruh pada pencapaian tujuan perusahaan karena dapat meningkatkan kinerja karyawan dan kinerja perusahaan.

Natrabu Minang Restoran Bali merupakan salah satu perusahaan yang bergerak dibidang bisnis masakan tradisional Minang Kabau. Perusahaan https://doi.org/10.24843/SOCA.2018.v12.i02.p05 
ini merupakan salah satu bagian dari bisnis besar Natrabu Minang Kabau, dimana bentuk dari bagian bisnis Natrabu ini ialah Natrabu Travel Biro, Natrabu Grup, dan Natrabu Minang Restoran. Bisnis ini sudah menempati atau pun menyebar di beberapa pulau maupun wilayah yaitu Jakarta, Bali dan Kuala Lumpur. Hal ini untuk memenangkan persaingan antara perusahaan yang sejenis, Natrabu Minang Restoran Bali harus selalu meningkatkan kualitas sumber daya manusia untuk mencapai efisiensi operasi dan peningkatan kinerja karyawan maupun operasi. Adapun dalam rangka meningkatkan kinerja karyawan, maka diperlukan suatu faktor pendorong. Salah satu faktor pendorong tersebut adalah sistem penggajian. Sistem penggajian yang diharapkan oleh perusahaan adalah sistem penggajian yang dapat mengurangi biaya produksi dan mencapai tujuan organisasi, sedangkan karyawan membutuhkan sistem penggajian yang adil dan taat asas.

Menurut Armstrong dan Murlis (2001) sistem penggajian adalah pengaturan dalam organisasi mengenai apa dan bagaimana harus dibayar atas pekerjaan yang mereka lakukan. Sistem penggajian mengatur imbalan berdasarkan seberapa baik karyawan sebagai individu, tim atau organisasi bekerja dan juga mengatur imbalan berdasarkan kontribusi, tingkat kemampuan (kompetensi) atau ketrampilan yang telah mereka capai. Oleh karena itu, dalam suatu organisasi ataupun perusahaan sangat perlu diperhatikan sistem penggajiannya. Sehingga mampu memberikan output yang baik terhadap kinerja karyawan itu sendiri. Sedangkan yang kita ketahui menurut Lawler (1984) terdapat dua dimensi dalam mempertimbangkan desain strategi untuk sistem penggajian. Pertama adalah dimensi struktural (praktek dan prosedur formal) dan yang kedua adalah dimensi proses (komunikasi dan proses pengambilan keputusan). Dari hal tersebut akan muncul hasil output yang kita inginkan, dan semua hal itu tidak terlepas dari tingginya kinerja karyawan yang kita miliki. Karena Output dari perusahaan akan sangat dipengaruhi ataupun berdampak terhadap kinerja karyawan. Dimana dapat kita lihat pengertian dari kinerja karyawan, menurut Mangkunegara (2000), kinerja adalah hasil secara kualitas dan kuantitas yang dicapai oleh seorang pegawai dalam melaksanakan tugasnya sesuai dengan tanggung jawab yang diberikan kepadanya. Tinggi rendahnya kinerja karyawan berkaitan erat dengan sistem pemberian penghargaan yang diterapkan oleh lembaga atau organisasi tempat mereka bekerja. Sedangkan dalam proses pemberian penghargaan yang tidak tepat dapat berpengaruh terhadap peningkatan kinerja seseorang.

Penelitian ini bertujuan untuk mengetahui pengaruh sistem penggajian terhadap pemberdayaan karyawan, untuk mengetahui pengaruh sistem penggajian terhadap kepuasan kerja, serta mengetahui pengaruh sistem penggajian terhadap komitmen organisasi. Penelitian ini dilakukan karena melihat uniknya cara pandang perusahaan Natrabu Minang Restoran Bali dalam penentuan Sistem Penggajian terhadap Kinerja Karyawannya.

\section{METODE PENELITIAN}

\section{Lokasi dan Waktu Penelitian}

Penelitian ini dilakukan pada Perusahaan Natrabu Minang Restauran Bali di J1. By Pass Ngurah Rai 163 
Sanur, Denpasar Selatan, Bali. Penelitian ini dilaksanakan mulai bulan September 2017 hingga agustus 2018. Pemilihan lokasi penelitian ditentukan dengan metode purposive yaitu suatu teknik penentuan lokasi penelitian secara sengaja berdasarkan pertimbangan tertentu. Pertimbangan dalam pemilihan lokasi penelitian adalah sebagai berikut:

1. Perusahaan Natrabu Minang Restoran Bali merupakan salah satu rumah makan minang yang terkenal di Bali. Hal ini dibuktikan dengan cita rasa yang khas serta pengunjung yang banyak baik luar maupun lokal.

2. Perusahaan Natrabu Minang Restoran Bali memiliki banyak karyawan, sehingga mampu mencukupi sampel penelitian.

3. Karyawan banyak keluar dengan alasan gaji yang kurang mencukupi

\section{Data dan Pengumpulan Data Jenis data}

Jenis data yang digunakan dalam penelitian ini dikelompokkan menjadi dua yaitu sebagai berikut:

1. Data kualitatif adalah data yang tidak dalam bentuk angka tetapi berupa uraian dan penjelasan yang tidak dapat dihitung. Pada penelitian ini data kualitatif yang dicari adalah sejarah dan gambaran umum, serta struktur organisasi Perusahaan Natrabu Minang Restoran Bali dan hal-hal yang berkaitan dengan perusahaan tersebut.

2. Data kuantitatif adalah data yang dapat dihitung dan dalam bentuk angka-angka dengan satuan tertentu. Data kuantitatif dalam penelitian ini yaitu data yang diisi oleh karyawan Natrabu Minang Restoran Bali melalui kuesioner.

\section{Sumber data}

Data dalam penelitian ini diperoleh dari sumber primer dan sumber sekunder sebagai berikut:

1. Data primer

Data primer adalah sumber data yang diperoleh langsung dari responden melalui kuisioner yang berupa sebuah pernyataan terhadap objek yang diteliti. Kuesioner meliputi identitas responden, pengaruh sistem penggajian, pemberdayaan, kepuasan kerja, dan komitmen organisasi. Responden tersebut diantaranya: semua karyawan yang bekerja di perusahaan Natrabu Minang Restoran Bali tanpa melihat perbedaan divisi.

2. Data sekunder

Data sekunder adalah sumber data yang diperoleh melalui data yang telah diteliti dan dikumpulkan oleh pihak lain yang berkaitan dengan permasalahan penelitian. Data sekunder dalam penelitian ini diperoleh dari berbagai bahan pustaka, baik berupa buku, jurnal-jurnal, dan dokumen lainnya yang berhubungan dengan materi kajian.

\section{Metode pengumpulan data}

Berikut metode pengumpulan data yang akan dilakukan:

1. Kuesioner

Kuesioner merupakan metode pengumpulan data dengan cara memberikan daftar pertanyaan atau pernyataan yang disusun secara sistematik kepada responden sebagai sampel (Hartono, 2004).

2. Wawancara

Teknik pengumpulan melaui wawancara yang dilakukan dengan Manajer Natrabu Minang Restoran Bali, data yang akan dikumpulkan melalui metode ini antara lain: gambaran umum Natrabu Minang Restoran Bali. 


\section{Observasi}

Teknik observasi digunakan untuk melengkapi data yang telah diperoleh dari wawancara yaitu dengan adanya pengamatan dari peneliti baik secara langsung ataupun tidak langsung pada obyek yang diteliti (Umar, 2000). Tujuan teknik ini di dalam penelitian untuk menggali informasi yang lebih relevan. Observasi atau pengamatan langsung di Natrabu Minang Restoran Bali.

\section{Populasi dan Sampel}

Menurut Sugiyono (2014) sampel adalah bagian dari jumlah yang dimiliki oleh populasi tersebut. Metode pengambilan sampel yang digunakan adalah purposive sampling yaitu teknik untuk menentukan sampel penelitian dengan beberapa pertimbangan tertentu yang bertujuan agar data yang diperoleh nantinya bisa lebih representatif (Sugiyono, 2010), artinya sampel data yang diambil sebanyak 35 responden dari 39 karyawan. Hal ini dikarenakan 4 karyawan lainnya tidak memenuhi kriteria dalam penilitian penulis. Adapun kriteria pemilihan sampel terbagi menjadi kriteria inklusi dan eksklusi. Kriteria inklusi merupakan kriteria sampel berdasarkan tujuan peneliti, sedangkan kriteria eksklusi merupakan kriteria yang menyebabkan calon responden dikeluarkan dari kelompok penelitian.

\section{Variabel Penelitian dan Pengukuran}

Variabel-variabel yang akan dianalisis dalam penelitian ini adalah sistem penggajian, pemberdayaan, kepuasan kerja, dan komitmen organisasi. Indikator merupakan salah satu komponen yang dijadikan alat ukur mengenai pengaruh sistem penggajian terhadap kinerja karyawan, sehingga mencapai kepuasan kerja dan komitmen karyawan terhadap perusahaan Natrabu Minang Restoran Bali.

\section{Pengukuran variabel}

Pada pelaksanaan penelitian ini, peneliti memberikan skala untuk mengukur variabel-variabel yang akan diteliti melalui anggaran responden dengan menggunakan skala likert. Skala likert adalah skala yang didasarkan pada penjumlahan sikap responden dalam merespon pernyataan berkaitan dengan indikator-indikator suatu konsep atau variabel yang sedang diukur.

Tabel 1. Kategori Skor Pengaruh Sistem Penggajian, Pemberdayaan, Kepuasan Kerja dan Komitmen Organisasi terhadap Kinerja Karyawan di Natrabu Minang Restoran Bali

\begin{tabular}{ccl}
\hline Skor & Interval Skor & \multicolumn{1}{c}{ Kategori } \\
\hline 1 & $1 \mathrm{~s} / \mathrm{d} 1,7$ & Sangat Tidak Baik / Sangat Rendah \\
2 & $1,8 \mathrm{~s} / \mathrm{d} 2,4$ & Tidak Baik / Rendah \\
3 & $2,5 \mathrm{~s} / \mathrm{d} \mathrm{3,1}$ & Cukup \\
4 & $3,2 \mathrm{~s} / \mathrm{d} \mathrm{3,8}$ & Baik/ Tinggi \\
5 & $3,9 \mathrm{~s} / \mathrm{d} \mathrm{4,5}$ & Sangat Baik / Sangat Tinggi \\
\hline
\end{tabular}

Sumber: (Umar, dalam Amryyanti 2012)

\section{Analisis Structural Equation Modeling (SEM)}

Dalam penelitian ini, analisis data dengan statistika digunakan SEM-PLS bantuan software Smart
PLS. Keunggulan analisis dengan PLS menurut Wold (1985 dalam Ghozali 2011) menyatakan bahwa PLS merupakan metode analisis yang powerfull oleh karena tidak 
didasarkan banyak asumsi. Data tidak harus berdistribusi normal multivariate (indikator dengan skala kategori, ordinal, inteval, dan sampai ratio) dapat digunakan pada model yang sama, sampel tidak harus besar. PLS dapat menganalisis sekaligus konstruk yang dibentuk dengan indicator refleksif dan indikator formatif dan hal ini tidak mungkin dijalankan dalam CBSEM karena akan terjadi unidentified model.

Menurut Ghozali (2011) tujuan PLS adalah membantu peneliti untuk mendapatkan nilai variabel laten untuk tujuan prediksi. Estimasi parameter yang didapat dengan PLS dapat dikatagorikan menjadi tiga yaitu:

1. Weight estimate, dimana diperlukan untuk menciptakan skor variabel laten.

2. Memiliki cerminan estimasi jalur (path estimate) yang mampu menghubungkan variabel laten satu dengan variabel laten lainnya, dan blok indikatornya (loading).

3. Keterkaitan dengan means dan lokasi parameter (nilai konstanta regresi) untuk indikator dan variabel laten.

\section{HASIL DAN PEMBAHASAN}

\section{Analisis Data}

\section{Karakteristik responden}

Peneliti bermaksud untuk mendiskripsikan data melalui penjabaran atas karakteristik data responden yang dimiliki secara transparan berdasarkan data demografi yakni karyawan Natrabu Minang Restoran Bali mana, status sebagai karyawan, jenis kelamin, usia, status pekerjaan, pendidikan terakhir dan pendapatan perbulan. Berdasarkan hasil penelitian menunjukan, bahwa responden yang mendominasi penelitian ini merupakan karyawan Natrabu Minang Restoran Bali sebanyak 29 responden dengan persentase $82,9 \%$ berjenis kelamin pria sedangkan 6 responden dengan persentase $17,1 \%$ berjenis kelamin wanita. Demografi berdasarkan usia yang mendominasi adalah 21-25 tahun sebanyak 21 responden dan persentase $60 \%$, usia 26-30 tahun sebanyak 9 responden dan persentase $25,7 \%$, usia dibawah 20 tahun sebanyak 3 responden dan persentase $8,6 \%$, usia diatas 30 tahun sebanyak 2 responden dan persentase $5,7 \%$. Responden dengan pendidikan terakhir penelitian ini di dominasi oleh responden dengan pendidikan terakhir yakni SMA sebanyak 26 responden dengan persentase $74,3 \%$, responden dengan SMP sebanyak 9 dengan persentase $25,7 \%$.

\section{Analisis Deskriptif Kontruk sistem penggajian}

Adapun hasil Tabel 2, dimana analisis deskriptif tentang konstruk sistem penggajian, secara keseluruhan menghasilkan capaian skor sebesar 3,58 dan berada pada kategori baik, artinya sistem penggajian pada Natrabu Minang Restoran Bali dinilai sudah baik. Indikator sentralisasidesentralisasi merupakan indicator dengan rata-rata tertinggi sebesar 3,7 sedangkan indikator terendah adalah basis penggajian dengan rata-rata sebesar 3,5. 
Tabel 2. Capaian Skor Konstruk Sistem Penggajian

\begin{tabular}{|c|c|c|c|c|c|c|c|c|c|c|}
\hline \multirow[t]{2}{*}{ Pertanyaan } & \multicolumn{2}{|c|}{ STS } & \multicolumn{2}{|c|}{ TS } & \multicolumn{2}{|r|}{$\mathrm{S}$} & \multicolumn{2}{|c|}{ SS } & \multirow{2}{*}{$\begin{array}{l}\text { Skor } \\
\text { Total }\end{array}$} & \multirow{2}{*}{$\begin{array}{l}\text { Capaian } \\
\text { Skor }\end{array}$} \\
\hline & $\mathrm{F}$ & $\%$ & $\mathrm{~F}$ & $\%$ & $f$ & $\%$ & $f$ & $\%$ & & \\
\hline $\begin{array}{l}\text { Gaji berdasarkan } \\
\text { target pekerjaan }\end{array}$ & 2 & 5.7 & 1 & 2.9 & 9 & 25.7 & 23 & 65.7 & 123 & 3.5 \\
\hline $\begin{array}{l}\text { Gaji berdasarkan } \\
\text { tingkat jabatan yang } \\
\text { dimiliki }\end{array}$ & 2 & 5.7 & 1 & 2.9 & 5 & 14.3 & 27 & 77.1 & 127 & 3.6 \\
\hline $\begin{array}{l}\text { Sistem pengajian yang } \\
\text { diterapkan telah } \\
\text { distandardisasi oleh } \\
\text { perusahaan }\end{array}$ & 2 & 5.7 & 1 & 2.9 & 4 & 11.4 & 28 & 80.0 & 128 & 3.7 \\
\hline $\begin{array}{l}\text { Keterlibatan karyawan } \\
\text { dalam proses gaji }\end{array}$ & 1 & 2.9 & 2 & 5.7 & 9 & 25.7 & 23 & 65.7 & 124 & 3.5 \\
\hline Capaian Skor Keseluru & ian & & & & & & & & & 3.58 \\
\hline Kategori Skor & & & & & & & & & & Baik \\
\hline
\end{tabular}

Sumber: Kuesioner diolah, 2018

\section{Kontruk Pemberdayaan Karyawan}

Adapun hasil Tabel 3, dimana analisis deskriptif tentang konstruk pemberdayaan karyawan, secara keseluruhan menghasilkan rata-rata sebesar 3,58 dan berada pada kategori baik, artinya pemberdayaan karyawan pada Natrabu Minang Restoran Bali dinilai sudah baik. Indikator kemampuan den keberpengaruhan merupakan indicator dengan rata-rata tertinggi sebesar 3,7 sedangkan indicator terendah adalah kebermaknaan dengan rata-rata sebesar 3,3.

Tabel 3. Capaian Skor Konstruk Pemberdayaan Karyawan

\begin{tabular}{|c|c|c|c|c|c|c|c|c|c|c|}
\hline \multirow[t]{2}{*}{ Pertanyaan } & \multicolumn{2}{|c|}{ STS } & \multicolumn{2}{|c|}{ TS } & \multicolumn{2}{|c|}{$\mathrm{S}$} & \multicolumn{2}{|c|}{ SS } & \multirow{2}{*}{$\begin{array}{l}\text { Skor } \\
\text { Total }\end{array}$} & \multirow{2}{*}{$\begin{array}{l}\text { Capaian } \\
\text { Skor }\end{array}$} \\
\hline & $\mathrm{F}$ & $\%$ & $F$ & $\%$ & $\mathrm{~F}$ & $\%$ & $\mathrm{~F}$ & $\%$ & & \\
\hline $\begin{array}{l}\text { Berartinya sebuah } \\
\text { pekerjaan }\end{array}$ & 2 & 5.7 & 4 & 11.4 & 12 & 34.3 & 17 & 48.6 & 114 & 3.3 \\
\hline $\begin{array}{l}\text { Kemampuan dalam } \\
\text { penyelesaian } \\
\text { pekerjaan }\end{array}$ & 1 & 2.9 & 2 & 5.7 & 3 & 8.6 & 29 & 82.9 & 130 & 3.7 \\
\hline $\begin{array}{l}\text { Keputusan sendiri } \\
\text { dalam melaksanakan } \\
\text { pekerjaan }\end{array}$ & 1 & 2.9 & 3 & 8.6 & 5 & 14.3 & 26 & 74.3 & 126 & 3.6 \\
\hline $\begin{array}{l}\text { Memiliki kontrol } \\
\text { yang besar terhadap } \\
\text { bagian/departemen } \\
\text { saya }\end{array}$ & 1 & 2.9 & 2 & 5.7 & 3 & 8.6 & 29 & 82.9 & 130 & 3.7 \\
\hline Capaian Skor Keselur & uh & & & & & & & & & 3.58 \\
\hline Kategori Skor & & & & & & & & & & Baik \\
\hline
\end{tabular}

Sumber: Kuesioner diolah, 2018 


\section{Kontruk Kepuasan Kerja}

Adapun hasil Tabel 4, dimana analisis deskriptif tentang konstruk kepuasan kerja, secara keseluruhan menghasilkan rata-rata sebesar 3,68 dan berada pada kategori baik, artinya kepuasan kerja pada Natrabu Minang
Restoran Bali dinilai sudah baik. Indikator nature of work dan benefit merupakan indicator dengan rata-rata tertinggi sebesar 3,7 sedangkan indicator terendah adalah coworkers dengan rata-rata sebesar 3,6.

Tabel 4. Capaian Skor Konstruk Kepuasan Kerja

\begin{tabular}{|c|c|c|c|c|c|c|c|c|c|c|}
\hline \multirow[t]{2}{*}{ Pertanyaan } & \multicolumn{2}{|c|}{ STS } & \multicolumn{2}{|c|}{ TS } & \multicolumn{2}{|c|}{$\mathrm{S}$} & \multicolumn{2}{|c|}{ SS } & \multirow{2}{*}{$\begin{array}{l}\text { Skor } \\
\text { Total }\end{array}$} & \multirow{2}{*}{$\begin{array}{l}\text { Capaian } \\
\text { Skor }\end{array}$} \\
\hline & $\mathrm{F}$ & $\%$ & $\mathrm{~F}$ & $\%$ & $\mathrm{~F}$ & $\%$ & $\mathrm{~F}$ & $\%$ & & \\
\hline $\begin{array}{ll}\text { Keadilan } & \text { sistem } \\
\text { penggajian } & \end{array}$ & 2 & 5.7 & 1 & 2.9 & 4 & 11.4 & 28 & 80.0 & 128 & 3.7 \\
\hline $\begin{array}{l}\text { Secara } \\
\text { keseluruhan rekan } \\
\text { kerja saya sangat } \\
\text { menyenangkan }\end{array}$ & 1 & 2.9 & 3 & 8.6 & 4 & 11.4 & 27 & 77.1 & 127 & 3.6 \\
\hline $\begin{array}{l}\text { Perlakuan terhadap } \\
\text { karyawan }\end{array}$ & 1 & 2.9 & 2 & 5.7 & 3 & 8.6 & 29 & 82.9 & 130 & 3.7 \\
\hline $\begin{array}{ll}\text { Fasilitas } & \text { yang } \\
\text { diberikan } & \end{array}$ & 1 & 2.9 & 2 & 5.7 & 3 & 8.6 & 29 & 82.9 & 130 & 3.7 \\
\hline
\end{tabular}

Capaian Skor Keseluruhan

3.68

Katrogori Skor

Baik

Sumber: Kuesioner diolah, 2018

\section{Kontruk Komitmen Organisasi}

Adapun hasil Tabel 5, dimana analisis deskriptif tentang konstruk komitmen organisasi, secara keseluruhan menghasilkan rata-rata sebesar 3,67 dan berada pada kategori baik, artinya komitmen organisasi pada Natrabu Minang Restoran Bali dinilai baik. Indikator komitmen afektif merupakan indicator dengan rata-rata tertinggi sebesar 3,7 sedangkan indicator terendah adalah komitmen normatif dengan rata-rata sebesar 3,5.

Tabel 5. Capaian Skor Konstruk Komitmen Organisasi

\begin{tabular}{|c|c|c|c|c|c|c|c|c|c|c|}
\hline \multirow[t]{2}{*}{ Pertanyaan } & \multicolumn{2}{|c|}{ STS } & \multicolumn{2}{|c|}{ TS } & \multicolumn{2}{|l|}{ S } & \multicolumn{2}{|l|}{ SS } & \multirow{2}{*}{$\begin{array}{l}\text { Skor } \\
\text { Total }\end{array}$} & \multirow{2}{*}{$\begin{array}{l}\text { Capaian } \\
\text { Skor }\end{array}$} \\
\hline & $\mathrm{F}$ & $\%$ & $\mathrm{f}$ & $\%$ & $\mathrm{f}$ & $\%$ & $\mathrm{~F}$ & $\%$ & & \\
\hline $\begin{array}{l}\text { Perusahaan ini } \\
\text { berarti secara } \\
\text { pribadi bagi saya }\end{array}$ & 2 & 5.7 & 1 & 2.9 & 3 & 8.6 & 29 & 82.9 & 129 & 3.7 \\
\hline $\begin{array}{l}\text { Berpindah dari satu } \\
\text { perusahaan ke } \\
\text { perusahaan lain }\end{array}$ & 1 & 2.9 & 2 & 5.7 & 8 & 22.9 & 24 & 68.6 & 125 & 3.6 \\
\hline
\end{tabular}




\begin{tabular}{llllllllllll}
\hline $\begin{array}{l}\text { Tetap bekerja di } \\
\text { perusahaan yang }\end{array}$ & 1 & 2.9 & 2 & 5.7 & 5 & 14.3 & 27 & 77.1 & 128 & 3.7 \\
\hline Capaian Skor Keseluruhan & & & & & & & & $\mathbf{3 . 6 7}$ \\
\hline
\end{tabular}

Sumber: Kuesioner diolah, 2018

\section{Hasil Analisis Uji Validitas}

Instrumen dapat dikatakan valid apabila instrumen tersebut dapat mengukur yang seharusnya diukur (Cooper dan Schindler, 2014). Dalam penelitian ini uji validitas akan menggunakan metoda Convergent validity dan discriminant validity dengan bantuan SmartPLS 3.0. Berdasarkan pada metode penelitian yang telah diuraikan, sebelum melakukan analisis data lebih lanjut, langkah pertama yang dilakukan terlebih dahulu adalah memasukan data mentah dengan format excel CSV comma delimited, setelah data mentah dimasukan maka tahapan analisis data dapat dilakukan.

\section{Pengujian model struktural (inner model)}

Modal struktural pada PLS dievaluasi dengan menggunakan $R$ Square $\left(\mathrm{R}^{2}\right)$ yang dapat dilihat pada Gambar 1. Berikut adalah Nilai RSquare yang terlihat pada Tabel 6 .

Tabel 6. Nilai R-Square

\begin{tabular}{lcc}
\hline & $R$ Square & $R$ Square Adjusted \\
\hline Kepuasan Kerja & 0,734 & 0,726 \\
Komitmen Organisasi & 0,813 & 0,807 \\
Pemberdayaan Karyawan & 0,826 & 0,821
\end{tabular}

Sumber: output SmartPLS diolah, 2018

\section{Pengujian hipotesis}

Adapun pengujian hipotesis, nilai $t$-statistic yang dihasilkan dari output PLS dibandingkan dengan nilai t-tabel. Output PLS merupakan estimasi variabel laten yang merupakan linier agregat dari indicator. Kriteria pengujian adalah sebagai berikut.

1. Nilai t-hitung lebih besar dari nilai kritis $(\geq 1,96)$
2. Nilai standardized path coefficient $(p)<0,05$

Perihal variabel dependen dan nilai koefisien pada path (ß) untuk variabel indipenden yang kemudian nilai signifikan dinilai berdasarkan nilai T-statistic setiap path. Adapun model struktural atau inner model dapat dilihat pada Tabel 7 dibawah ini.

Tabel 7. Hasil Pengujian Hipotesis

\begin{tabular}{lcc}
\hline & T-Hitung & P-Values \\
\hline Sistem Penggajian $\rightarrow$ Pemberdayaan & 12,512 & 0.000 \\
Sistem Penggajian $\rightarrow$ Kepuasan Kerja & 5,911 & 0.000 \\
Sistem Penggajian $\rightarrow$ Komitmen Organisasi & 8,158 & 0.000 \\
\hline
\end{tabular}

Sumber: output SmartPLS diolah, 2018 
Secara ringkas rangkuman hasil pengujian hipotesis dalam penelitian ini dapat dilihat dalam Tabel 8 berikut ini:

Tabel 8. Rangkuman Hasil Uji Hipotesis

\begin{tabular}{clc}
\hline \multicolumn{1}{c}{ Pernyataan hipotesis } & Keterangan \\
\hline H1 & $\begin{array}{l}\text { Sistem penggajian berpengaruh } \\
\text { signifikan terhadap pemberdayaan } \\
\text { karyawan }\end{array}$ & Diterima \\
H2 & $\begin{array}{l}\text { Sistem penggajian berpengaruh } \\
\text { signifikan terhadap kepuasan kerja } \\
\text { H3 }\end{array}$ & $\begin{array}{l}\text { Sistem penggajian berpengaruh } \\
\text { signifikan terhadap komitmen } \\
\text { organisasi }\end{array}$ \\
\hline
\end{tabular}

Sumber: output SmartPLS diolah, 2018

Berdasarkan hasil Tabel 8, pengujian ketiga hipotesis dalam penelitian ini, dapat disimpulkan bahwa ketiga hipotesis diterima.

\section{Pengujian Model Pengukuran (Outer Model) \\ Convergent Validity}

Adapun Convergent validity dari measurement model dengan indikator refleksif dapat diketahui dan dilihat dari korelasi antara score item/indikator dengan score konstruknya. Indikator individu dianggap reliabel jika memiliki nilai korelasi di atas 0,70 Namun demikian pada riset tahap pengembangan skala, loading 0,50 sampai 0,60 masih dapat diterima (Imam Ghozali, 2011).

1. Convergent validity untuk konstruk Sistem Penggajian (X)

Konstruk Sistem Penggajian yang terdiri dari 4 indikator yaitu X1, X2, X3 dan X4. Berdasarkan hasil output Smart PLS, X1memiliki loading sebesar 0,754, X2 memiliki loading sebesar 0,921, X3 memiliki loading sebesar 0,945 dan X4 memiliki loading sebesar 0,952. Berdasarkan nilai loading tersebut, maka konstruk Sistem Penggajian telah memenuhi convergent validity.
2. Convergent validity untuk konstruk Pemberdayaan Karyawan (Y1)

Konstruk Pemberdayaan Karyawan yang terdiri dari 4 indikator yaitu Y1.1, Y1.2, Y1.3 dan Y1.4. Berdasarkan hasil output Smart PLS, Y1.1 memiliki loading sebesar 0,780, Y1.2 memiliki loading sebesar 0,914, Y1.3 memiliki loading sebesar 0,935 dan Y1.4 memiliki loading sebesar 0,908. Berdasarkan nilai loading tersebut, maka konstruk Pemberdayaan Karyawan telah memenuhi convergent validity.

3. Convergent validity untuk konstruk Kepuasan Kerja (Y2)

Konstruk Kepuasan Kerja yang terdiri dari 4 indikator yaitu Y2.1, Y2.2, Y2.3 dan Y2.4. Berdasarkan hasil output Smart PLS, Y2.1 memiliki loading sebesar 0,950, Y2.2 memiliki loading sebesar 0,944, Y2.3 memiliki loading sebesar 0,968 dan Y2.4 memiliki loading sebesar 0,969. Berdasarkan nilai loading tersebut, maka konstruk Kepuasan Kerja telah memenuhi convergent validity.

4. Convergent validity untuk konstruk Komitmen Organisasi (Y3)

Konstruk Komitmen Organisasi yang terdiri dari 3 indikator yaitu Y3.1, Y3.2, dan Y3.3. Berdasarkan hasil 
output Smart PLS, Y3.1 memiliki loading sebesar 0,927, Y3.2 memiliki loading sebesar 0,922, dan Y3.3 memiliki loading sebesar 0,946. Berdasarkan nilai loading tersebut, maka konstruk Komitmen Organisasi telah memenuhi convergent validity.

\section{Discriminant Validity}

Adapun Discriminat validity dari model pengukuran dengan indikator refleksif dapat dinilai ataupun diketahui berdasarkan cross loading pengukuran dengan konstruk. Jika korelasi konstruk dengan item pengukuran lebih besar dari pada ukuran konstruk lainnya, maka hal itu menunjukkan bahwa konstruk laten memprediksi ukuran pada blok mereka lebih baik daripada ukuran pada blok lainnya. Hal ataupun langkah lainnya yang mampu dilakukan untuk mengukur discriminat validity adalah melihat nilai square root of average variance extracted (AVE). Nilai yang disarankan adalah di atas 0,5 . Berikut adalah nilai AVE dalam penelitian yang dihasilkan pada Tabel 9.

Tabel 9. Average Variance Exracted (AVE)

\begin{tabular}{lc}
\hline \multicolumn{1}{c}{ Konstruk } & Average Variance Extracted (AVE) \\
\hline Sistem Penggajian & 0,804 \\
Pemberdayaan & 0,784 \\
Kepuasan Kerja & 0,917 \\
Komitmen Organisasi & 0,868 \\
\hline Sumber: output SmartPLS diolah, 2018
\end{tabular}

Berdasarkan hasil dari Tabel 9, dimana memberikan nilai AVE di atas 0,5 untuk semua konstruk, Sistem Penggajian $=0,804$, Pemberdayaan $=$ 0,784, Kepuasan Kerja $=0,917$, Komitmen Organisasi $=0,868$, hal ini berarti semua konstruk memiliki discriminat validity yang tinggi.

\section{Deskripsi Pengaruh Sistem Penggajian Terhadap Pemberdayaan Karyawan}

Berdasarkan Tabel 7, maka hasil uji nilai t-hitung untuk pengaruh sistem penggajian terhadap pemberdayaan karyawan sebagai berikut:

Hipotesis satu menyatakan bahwa sistem penggajian berpengaruh signifikan terhadap pemberdayaan karyawan. Setelah dilakukan pengujian hipotesis, konstruk Sistem Penggajian berpengaruh signifikan terhadap Pemberdayaan Karyawan, terlihat dari nilai t-hitung $(12,512)>\mathrm{t}-$ tabel $(1,96)$ dan nilai $\mathrm{p}$ sebesar $0,000<$ 0,05 . Berarti bahwa sistem penggajian berpengaruh signifikan terhadap pemberdayaan karyawan.

\section{Deskripsi Pengaruh Sistem Penggajian Terhadap Kepuasan Kerja}

Berdasarkan Tabel 7, maka hasil uji nilai t-hitung untuk pengaruh sistem penggajian terhadap kepuasan kerja sebagai berikut:

Hipotesis dua menyatakan bahwa sistem penggajian berpengaruh signifikan terhadap kepuasan kerja. Setelah dilakukan pengujian hipotesis, konstruk Sistem Penggajian berpengaruh signifikan terhadap Kepuasan Kerja, terlihat dari nilai thitung $(5,911)>$ t-tabel $(1,96)$ nilai $\mathrm{p}$ sebesar $0,000<0,05$. Berarti bahwa sistem penggajian berpengaruh signifikan terhadap kepuasan kerja. 


\section{Deskripsi Pengaruh Sistem Penggajian Terhadap Komitmen Organisasi}

Berdasarkan Tabel 7, maka hasil uji nilai t-hitung untuk pengaruh sistem penggajian terhadap kepuasan kerja sebagai berikut:

Hipotesis tiga menyatakan bahwa sistem penggajian berpengaruh signifikan terhadap komitmen organisasi. Setelah dilakukan pengujian hipotesis, konstruk Sistem Penggajian berpengaruh signifikan terhadap Komitmen Organisasi, terlihat dari nilai t-hitung $(8,158)>\mathrm{t}$ tabel $(1,96)$ nilai $\mathrm{p}$ sebesar $0,000<$ 0,05 . Berarti bahwa sistem penggajian berpengaruh signifikan terhadap pemberdayaan karyawan.

\section{KESIMPULAN}

Berdasarkah hasil dari pembahasan penelitian, maka dapat diperoleh kesimpulan sebagai berikut.

1. Sistem Penggajian berpengaruh signifikan terhadap pemberdayaan karyawan. Konstruk Sistem Penggajian berpengaruh signifikan terhadap Pemberdayaan Karyawan, terlihat dari nilai thitung $(12,512)>$ t-tabel $(1,96)$ dan nilai p-value sebesar $0,000<0,05$.

2. Sistem Penggajian berpengaruh signifikan terhadap kepuasan kerja. Konstruk Sistem Penggajian berpengaruh signifikan terhadap Kepuasan Kerja, terlihat dari nilai t-hitung $(5,911)>$ t-tabel $(1,96)$ nilai $\mathrm{p}$-value sebesar $0,000<0,05$.

3. Sistem Penggajian berpengaruh signifikan terhadap komitmen organisasi. Konstruk Sistem Penggajian berpengaruh signifikan terhadap Komitmen Organisasi, terlihat dari nilai t-hitung $(8,158)>$ t-tabel $(1,96)$ nilai $\mathrm{p}$-value sebesar $0,000<0,05$.

\section{SARAN}

Adapun beberapa saran yang dapat diambil untuk penulisan penilitian ini, demi kebaikan hasil selanjutnya ialah sebagai berikut.

1. Sistem penggajian digunakan untuk dapat meningkatkan kinerja karyawan. Dimensi sistem penggajian yang dapat diprioritaskan untuk kinerja karyawan adalah dimensi sentralisasi-desentralisasi yang memiliki nilai tertinggi diantara dimensi sistem penggajian yang lainnya.

2. Untuk ukuran penilaian kinerja dapat menggunakan ukuran yang lebih objektif seperti penilaian dari manajer di perusahaan mengenai kinerja karyawan, produktivitas individual, absensi, bukan hanya penilaian dari kuesioner yang diisi sendiri oleh masing-masing karyawan.

3. Penelitian ini masih memiliki berbagai kelemahan dan kekurangan, oleh karenanya dipandang perlu dilakukan penelitian lebih lanjut untuk menghasilkan studi empiris terkait pengaruh sistem penggajian terhadap kinerja karyawan. Serta diharapkan dalam penelitian selanjutnya dapat menambahkan beberapa variabel serta menggunakan metode dan alat analisis terbaru, sehingga memberikan hasil penelitian yang lebih sempurna.

\section{UCAPAN TERIMAKASIH}

Terima Kasih kepada Manager Natrabu Minang Restoran Bali atas izin, arahan dan bimbingan dalam pelaksanaan penelitian ini, serta seluruh responden penelitian sehingga 
jurnal ini dapat disusun dengan tepat waktu.

\section{DAFTAR PUSTAKA}

Amryyanti, Ruth. 2012. Pengaruh Kualitas Layanan, Produk, Dan Kewajaran Harga Terhadap Kepuasan Dan Loyalitas Pelanggan pada LnC Skin Care Singaraja. Tesis Pascasarjana Universitas Udayana

Armstrong, M. dan H. Murlis. 2001. Reward Management Strategy and Practice Remuneration Strategy and Practice, The Art of HRD volume 9 (set of nine volume). Kogan Page, New Delhi

Astuti, S. D. 2004. Korelasi Pemberian Kompensasi Berupa Gaji dengan Kinerja Karyawan, Studi Kasus pada Karyawan PT X Medan. Jurnal Ilmiah Manajemen dan Bisnis. Vol 04:141-146.

Ghozali, Imam. 2006. Aplikasi Analisis Multivariate Dengan Sess. Cetakan Keempat. Badan Penerbit Universitas Diponegoro. Semarang

Ghozali, Imam. 2011. Aplikasi Analisis Multivariate Dengan Program IBM SPSS 19 (Edisi Kelima).
Semarang: Universitas

Diponegoro

Lawler. 1984. High Involvement Management: Participative Strategies for Improving Organizational Performance. CA: Jossey-Bass, San Francisco.

Mangkunegara, P. 2000. Manajemen Sumber Daya Manusia Perusahaan. PT. Remaja Rosda Karya, Bandung.

Padmi, Sri. K. D. Ni Md.2017. Analisis Perilaku Konsumen Terhadap Keputusan Pembelian Buah-buahan Segar di Moena Fresh. Skripsi Program Studi Agribisnis Fakultas Pertanian Universitas Udayana.

Sugiyono. 2010. Metode Penelitian Kualitatif. Bandung: Alfabeta.

Sugiyono.2014. Metode Penelitian Manajemen. Bandung: Alfabeta

Sunyoto, D. 2013. Metode dan Instrumen Penelitian Ekonomi dan Bisnis. Jakarta: PT Buku Seru

Syaumi, Istiana.2008. Kajian Dampak Sistem Penggajian Terhadap Kinerja Karyawan. Jakarta: Institut Pertanian Bogor. 